\title{
Heparin Use in Children
}

$\mathrm{H}^{\mathrm{s}}$ eparins are a group of related compounds comprised of a mixture of glycosaminoglycans usually derived from porcine intestine. They exert their effect by binding to antithrombin, which inhibits both activated factor $\mathrm{X}$ and thrombin via a specific pentasaccharide sequence. This binding results in a conformational change in antithrombin thereby increasing its activity several hundred fold. There are two formulations of heparins, unfractionated heparin (UFH) and low molecular weight heparin (LMWH), used in clinical practice. . Unfractionated heparin is used for both therapeutic anticoagulation and for maintaining vascular catheter patency via heparin locks and flushes.LMWH is used for therapeutic anticoagulation. Recommendations and dosing guidelines for use of heparin in children were established in 2004 during the 7th American College of Chest Physicians Conference on Antithrombotic and Thrombolytic Therapy (1).

The ubiquitous use of UFH for vascular catheter patency results in nearly all hospitalized patients being exposed to this agent. The guidelines for such use are derived from studies in adults, however despite the significantly smaller size of children, the amount of heparin used is often the same as that used for adults. The recent tragedy in which several premature babies, who received a 1000-fold overdose of heparin, died, brings to light the dangers of the use of heparin in children. While in this case, a medical error led to the tragedy, significant bleeding has occurred in other situations when the prescribed amount of heparin was given.

Is heparin really necessary for maintaining catheter patency? What is the evidence? One systematic review in neonates concluded that "... routine use of heparin for this purpose cannot be recommended." (2) Although heparin is routinely prescribed for maintaining catheter patency from simple peripheral intravenous catheters to central venous catheters and usually for arterial catheters as well, it must be understood that the evidence for this approach in pediatric patients is lacking. In fact, some studies have demonstrated that saline solution is as effective as heparin.

What is there to be learned from the medical tragedy involving heparin? Obviously, corrective measures to prevent medical errors need to be made, but this is true for all medications. With respect to heparin, physicians and nurses must understand that heparin is a potent anticoagulant, which can lead to significant bleeding at therapeutic concentrations. Its ubiquitous use has perhaps led to its dangers being taken 
for granted. All physicians, who order heparin even for line flushes and locks should be aware of the potential for bleeding complications and other adverse effects such as heparininduced thrombocytopenia. Lastly, the use of heparin for the maintenance of catheter patency should be re-examined via controlled clinical trials. - Guy Young, MD

\section{REFERENCES}

1. Monagle P, Chan A, Massicotte P, Chalmers E, Michelson AD 2004 Antithrombotic therapy in children: the Seventh ACCP Conference on Antithrombotic and Thrombolytic Therapy. Chest 126:645S-687S

2. Shah P, Shah V 2005 Continuous heparin infusion to prevent thrombosis and catheter occlusion in neonates with peripherally placed percutaneous central venous catheters. Cochrane Database Syst Rev 2005 Jul 20:CD00277

DOI: 10.1203/pdr.0b013e318031d4d1 